\title{
Editorial: Moral luck, social networking sites, and trust on the web
}

\author{
Maria C. Bottis • Frances S. Grodzinsky • \\ Herman T. Tavani
}

Published online: 7 October 2010

(C) Springer Science+Business Media B.V. 2010

In June 2009, the Eighth International Conference on Computer Ethics-Philosophical Enquiry (CEPE 2009) was held at Ionian University, Corfu, Greece. ${ }^{1}$ Four papers originally presented at that conference are included in this issue of Ethics and Information Technology. The selected papers examine a wide range of ICT-ethics related issues, which, at first glance, might seem too diverse to be included under the rubric of a conventional theme in applied ethics. On closer inspection, however, many readers will note that the topics discussed in these papers either overlap or intersect in certain areas, especially in their examination of some controversies that have recently emerged in the field. These include challenges posed by social networking sites such as Facebook, as well as concerns affecting trust in online environments. Another challenge addressed in one of the selected papers involves the role that "moral luck" can play in ICT ethics. In our effort to highlight the key ethical issues examined in these four papers, we categorize them under the theme "Moral Luck, Social Networking Sites, and Trust on the Web."

\section{C. Bottis}

Department of Archive and Library Sciences, Ionian University, Iannou Theotoki 72, Corfu 49100, Greece

e-mail: botti@otenet.gr

\section{F. S. Grodzinsky}

Department of Computer Science and Information Technology, Sacred Heart University, 5151 Park Ave, Fairfield, CT 06825,

USA

e-mail: grodzinskyf@sacredheart.edu

H. T. Tavani $(\square)$

Department of Philosophy, Rivier College, 420 Main St, Nashua, NH 03062, USA

e-mail: htavani@rivier.edu
The opening essay, by David Horner, examines the "problem of moral luck" in ICT ethics-a problem that Horner describes as an "unjustly neglected topic" within this field of applied ethics. Following a brief introduction and summary of Bernard Williams' argument that moral values, like other kinds of values, can be subject to moral luck, Horner applies Williams' scheme to ICT ethics. Horner also draws on Thomas Nagel's insights with respect to distinguishing four categories affecting moral luck: consequentialist luck, constitutive luck, circumstantial luck, and luck in antecedent conditions. Horner pays particular attention to the way that moral luck can impact our understanding of both professional responsibility and (what he calls) the "identification and attribution of responsibility." He then describes some ways in which the notion of moral luck can erode our understanding of the "scope of responsibility and agency," and he shows how this notion also poses a challenge for the kinds of theoretical approaches that are often used in analyzing moral questions that arise in designing and implementing ICTs. But Horner also points out that by analyzing moral luck in the context of ICT ethics, we can begin to think in new ways about some of our traditional concepts such as moral responsibility, accountability, and risk.

In the second essay, Michael Zimmer examines some ethical concerns affecting research on social networking sites (SNSs). In particular, he focuses on the "profile data" that was collected from the Facebook accounts of a cohort of students (at a university in the US) and then publicly released in 2008 by a group of researchers. Zimmer

\footnotetext{
${ }^{1}$ Fifty-five papers were presented at the CEPE 2009 Conference (Ionian University) June 26-28, 2009. The original versions of those papers are published in Maria Bottis, editor. Proceedings of the Eighth International Conference on Computer Ethics: Philosophical Enquiry. Athens, Greece: Nomiki Bibliothiki, 2009.
} 
believes that even though a "good-faith effort" may have been made to conceal the identity of the institution involved, as well as to protect the privacy of the data subjects who participated in the research, the privacy of the students was compromised because of the way the source of the data could be so "quickly identified." Among the topics examined in Zimmer's article are concerns affecting the nature of the informed-consent process used in collecting personal data on SNSs. Also examined are some issues affecting the role that institutional review boards play in research involving human subjects vis-à-vis SNSs. Zimmer also examines some strategies for anonymizing the personal data collected on SNSs before it is released to the public, and he considers some techniques for "identifying and respecting expectations of privacy" on Facebook and other SNSs. Acknowledging that the challenges and "conceptual muddles" generated by research in "social media spaces" (such as Facebook) may be difficult to overcome, Zimmer concludes his article by proposing three steps that he believes can be taken immediately to guide future research affecting SNSs.

The third paper, by Paul de Laat, addresses the question of how open-source communities handle the problem of trusting "invisible strangers" who contribute content to online forums on which others rely, and he asks whether these invisible strangers always have good intentions and/or adequate competencies? De Laat notes that, in one sense, the "hacker ethic" has contributed to current issues affecting trust in open-source software applications, and he points out that "substantial trust" "had to be assumed in cases involving contributors to "open" online forums such as Wikipedia. He also notes that rules and regulations were subsequently introduced and that these helped to lessen the need to "accept" all contributors as trustworthy. According to de Laat, the perspective for the future seems to be that open source design for software and (online) encyclopedias will probably converge towards a "mid-level of discretion" in relation to the amount of trust to be granted to "strangercontributors." In this way, he suggests that the design itself may help to eliminate the earlier practice where an unquestioning trust was granted to the anonymous user-contributor.
Whereas the second and third papers overlap in their examinations of controversial issues affecting SNSs and other kinds of online forums/communities, the third and fourth papers also share a common focus in that each examines an aspect of trust vis-à-vis the Web. In the fourth and final paper for this special issue, Judith Simon examines some philosophical accounts of the relationship between trust and knowledge in science, and she extends this analysis to the Web. Simon argues that trust and knowledge are fundamentally "entangled" in our epistemic practices and that we use knowledge to place or withdraw trust. Knowledge also provides insight into the sources of epistemic content as well as epistemic claims. She believes that although we may have a tendency to default to, or presume in favor of, trust, we remain and should remain "epistemically vigilant" and should "look for signs of insincerity and dishonesty in our attempts to know." Simon calls for "transparency" as a way to assess epistemic agents critically, and she applies this theory to the Web. Transparency becomes an especially pressing issue if we are attempting to trust unknown agents, which may or may not be human, over the Web. Simon also asserts that accounts of trust in humans may be insufficient for assessing trust on the web, and she believes that without such trust, knowledge is impossible.

The papers included in this special issue of Ethics and Information Technology, as in the case of many of the other papers originally presented at the CEPE 2009 Conference, illustrate some of the ways in which the field of ICT ethics continues to grow and evolve. When these four papers were originally presented in Corfu in late June 2009, they generated a series of questions that also led to spirited debate among the conference participants. We hope that you, too, will find these papers to be provocative and stimulating.

Also included in this volume are five book reviews. Three of these reviews critically examine Wendell Wallach and Colin Allen's recent book, Moral Machines: Teaching Robots Right from Wrong (Oxford, 2009). The present volume concludes with an annotated bibliography of forty recent books on ICT ethics. 